\title{
Contact fatigue life prediction of a bevel gear under spectrum loading
}

(C) The Author(s) 2019. This article is published with open access at link.springer.com and journal.hep.com.cn

\begin{abstract}
Rolling contact fatigue (RCF) issues, such as pitting, might occur on bevel gears because load fluctuation induces considerable subsurface stress amplitudes. Such issues can dramatically affect the service life of associated machines. An accurate geometry model of a hypoid gear utilized in the main reducer of a heavy-duty vehicle is developed in this study with the commercial gear design software MASTA. Multiaxial stress-strain states are simulated with the finite element method, and the RCF life is predicted using the Brown-Miller-Morrow fatigue criterion. The patterns of fatigue life on the tooth surface are simulated under various loading levels, and the RCF $S-N$ curve is numerically generated. Moreover, a typical torque-time history on the driven axle is described, followed by the construction of program load spectrum with the rain flow method and the Goodman mean stress equation. The effects of various fatigue damage accumulation rules on fatigue life are compared and discussed in detail. Predicted results reveal that the Miner linear rule provides the most optimistic result among the three selected rules, and the Manson bilinear rule produces the most conservative result.
\end{abstract}

Keywords bevel gear, rolling contact fatigue (RCF), multiaxial fatigue criterion, load spectrum, damage accumulation rule

Received February 21, 2019; accepted June 23, 2019

Pan JIA, Huaiju LIU ( $ه)$, Caichao ZHU

State Key Laboratory of Mechanical Transmissions, Chongqing University, Chongqing 400044, China

E-mail: huaijuliu@cqu.edu.cn

Wei WU

National Key Laboratory of Vehicular Transmission, Beijing Institute of Technology, Beijing 100081, China

Guocheng LU

Propulsion Development Department, Chongqing Changan New Energy Vehicles Technology, Chongqing 401133, China

\section{Introduction}

Bevel gears have been extensively used in main reducers and differentials of automobiles, aerospace devices, and printing devices due to their high mechanical efficiency, large loading capacity, low noise behavior, and capability for direct power transmission between two orthogonal shafts. Load fluctuation and considerable subsurface stress amplitude may cause rolling contact fatigue (RCF) issues, such as pitting, on bevel gears; these issues could dramatically affect the service life of associated machines. The prediction of RCF life of a bevel gear pair is imperative for reliability evaluation. Niemann et al. [1] developed the first version of FZG gear test rig and defined relevant experimental standards. Later on, this type of test rig was extensively applied in fatigue and tribological studies on involute parallel gears [2]. He et al. [3] investigated the effect of external load on involute gear contact fatigue life and curve-fitted the stress-life formula on the basis of numerical data. Fernandes and McDuling [4] found that surface contact fatigue is the most common cause of gear failure and can significantly reduce the loadcarrying capacity of components. Liu et al. [5] studied effects of surface roughness and residual stress on the contact fatigue performance of gears by using the modified Dang Van multiaxial fatigue criterion. Carpinteri et al. [6] conducted a comprehensive review of multiaxial fatigue under variable amplitude and random loading. Wang et al. $[7,8]$ predicted the RCF life of a wind turbine carburized gear by using multiaxial fatigue criteria. $\mathrm{Wu}$ et al. [9] evaluated six multiaxial fatigue criteria with life data obtained from proportional and non-proportional tensiontorsion fatigue tests on titanium alloy TC4. Zhu et al. [10] conducted a comparative evaluation of typical critical plane criteria by utilizing experimental datasets of four materials under uniaxial tension, torsion, and non-proportional multiaxial loadings.

Compared with involute gears, bevel gears have elicited less research attention. Litvin et al. [11] conducted a pioneering study on loaded tooth contact by using the finite 
element method; the contact pattern was predicted and proven by tests on spiral bevel gear drives. Sekercioglu and Kovan [12] experimentally studied the fatigue fracture of a bevel gear in an automotive differential and found that excessive contact stress is responsible for tooth pitting and the final fracture. Bhavi et al. [13] performed fatigue testing of spiral bevel gears and obtained the pinion's failure mode. Obtaining the $S-N$ curve through long-term fatigue tests is time consuming. Thus, experimentally acquired RCF $S-N$ curves of bevel gears have rarely been reported. Estimations of fatigue life with numerical methods, such as the finite element method, have become prevalent due to the development of simulation techniques. Ural et al. [14] summarized the applications of the finite element method and fracture mechanics in the prediction of cracks and estimation of the fatigue life of bevel gears in helicopters. Deng et al. [15] investigated contact and bending fatigue by using the cumulative fatigue criterion and stress-life equation.

In most engineering applications, gears experience timevarying loading histories due to the fluctuation of external torque. Liu et al. [16] developed a modular method to investigate the effect of load on the efficiency of a multirange hydromechanical transmission. Liu et al. [17] investigated the influence of work holding equipment errors on the mesh and loading behavior of face-hobbed hypoid gear by using an accurate mesh model established from a generated process. Medepalli and Rao [18] pointed out that the load characteristics of vehicles differ under varying road conditions and illustrated that the prediction of road load via numerical simulation is possible. The fatigue life under a constant load assumption cannot accurately describe damage evolution under a fluctuating load spectrum. Therefore, compilation of the load spectrum and selection of damage accumulation rules are crucial. Liu et al. [19] estimated the fatigue life of fan blades under random loading by considering the combined influence of stress amplitude and mean stress. Shinde et al. [20] utilized a modified rain flow counting method that allows the use of the Miner criterion to evaluate the fatigue life of structures under random loading. Mayer et al. [21] investigated the effect of cyclic loads below the endurance limit on fatigue damage in a series of variable amplitude loads.

According to these previous studies, accurate fatigue life estimation of bevel gears depends on the following prerequisites: Fatigue $S-N$ curve, load spectrum, and proper fatigue damage accumulation rule. Only a few studies on bevel gear fatigue life have considered these factors. To address this shortage, this study used the finite element method to simulate the multiaxial stress-strain states of subsurface material points and the RCF $S-N$ curve of bevel gear. The typical torque-time history on the driven axle was described using a typical truck load spectrum, and the standard load spectrum was constructed with the rain flow method and Goodman mean stress equation. Various fatigue damage accumulation rules were discussed. A diagram of the technique applied in this work is shown in Fig. 1.

\section{Numerical methodology}

To understand the contact fatigue behavior of a hypoid bevel gear in a heavy-duty vehicle, we investigated fatigue life under a given load spectrum by emphasizing the following aspects: Modeling of gear geometry and finite element contact analysis, fatigue life prediction of bevel gear under constant loading conditions on the basis of the Brown-Miller-Morrow multiaxial fatigue criterion, and compilation of load spectrum and fatigue estimations with various damage accumulation rules.

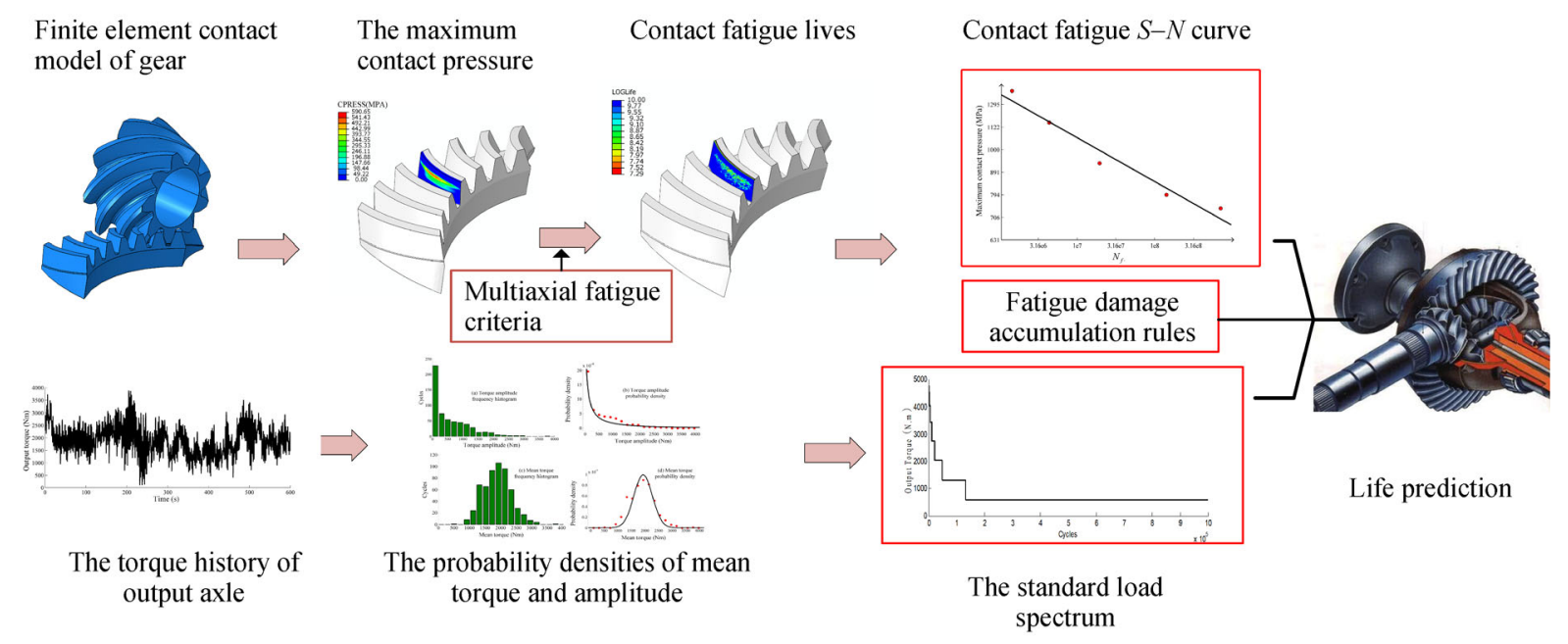

Fig. 1 Calculation flow chart. 


\subsection{Bevel gear contact finite element model}

Oerlikon and Gleason hypoid gears and spiral bevel gears are the most commonly used gear types in the main gearboxes of modern vehicles [22]. The Gleason-type hypoid gear was selected in this work, and the MC401AGMA/Gleason hypoid gear design module was obtained from the commercial gear design software MASTA. Table 1 shows the basic design parameters of a hypoid gear pair. Figure 2 shows the geometry of a Gleason hypoid gear pair.

A finite element contact analysis was conducted with the commercial software Abaqus/Standard 6.14. Seven teeth of the wheel were modeled in consideration of axisymmetric characteristics to reduce the computation time. The finite element type C3D10 was selected, and the mesh density at the tooth surface contact zone was sufficiently fine to guarantee convergence. Around 400000 elements were generated in the pinion and wheel. A rotating motion was applied on the driving pinion, and the output torque was applied on the engaged driven wheel, as shown in Fig. 3.

The gear material was $20 \mathrm{CrNiMo}$, and its fundamental mechanical properties are:

Young's modulus: $E=206 \mathrm{GPa}$;

Poisson's ratio: $v=0.3$;

Tensile strength: $\sigma_{\mathrm{s}}=1.3 \mathrm{GPa}$.

2.2 Fatigue life estimation under constant loading conditions

Under repeated gear meshing, the subsurface material points under the contacting surface exhibit complicated time-varying multiaxial stress-strain responses. Normal and shear components co-exist, and the mean values are generally non-zero [23]. Therefore, critical-plane-based multiaxial fatigue criteria are frequently used to determine the complicated stress-strain state and further employed for fatigue behavior analysis during the cycling contact period [24]. A widely accepted multiaxial criterion, the Brown-Miller criterion [25], was used in this work to evaluate the fatigue life under constant contact loading conditions.

Given that considerable mean stresses occur at critical material points, the modified Brown-Miller-Morrow criterion that considers the mean stress effect was used as follows [26]:

$$
\begin{aligned}
\frac{\Delta \gamma_{\max }}{2}+\frac{\Delta \varepsilon_{\mathrm{n}}}{2}= & 1.65 \frac{\left(\sigma_{\mathrm{f}}^{\prime}-\sigma_{\mathrm{m}}\right)}{2}\left(2 N_{\mathrm{f}}\right)^{b} \\
& +1.75 \varepsilon_{\mathrm{f}}^{\prime}\left(2 N_{\mathrm{f}}\right)^{c},
\end{aligned}
$$

where $\Delta \gamma_{\max }$ is the maximum shear strain range, $\Delta \varepsilon_{\mathrm{n}}$ is the normal strain range, $\sigma_{\mathrm{f}}^{\prime}$ is the fatigue strength coefficient, $\sigma_{\mathrm{m}}$ is the mean stress, $b$ is the fatigue strength exponent, $c$ represents the fatigue ductility exponent, $\varepsilon_{\mathrm{f}}^{\prime}$ is the fatigue ductility coefficient, and $N_{\mathrm{f}}$ is the cycle number to crack initiation.

Different loading levels were selected to generate the RCF $S-N$ curve of the bevel gear. Given that this methodology cannot predict the contact fatigue limit, the horizontal segment of a practical $S-N$ curve was not considered. The simulated $S-N$ curve was further used in the following life estimation under a given load spectrum.

\subsection{Compilation of the load spectrum}

Heavy-duty vehicles often operate under rough and

\begin{tabular}{|c|c|c|c|c|c|c|c|c|}
\hline $\begin{array}{l}\text { Hypoid } \\
\text { gear pair }\end{array}$ & $\begin{array}{l}\text { Number } \\
\text { of teeth }\end{array}$ & $\begin{array}{c}\text { Gear } \\
\text { module/mm }\end{array}$ & $\begin{array}{l}\text { Width of a } \\
\text { tooth } / \mathrm{mm}\end{array}$ & $\begin{array}{c}\text { Pitch } \\
\text { diameter } \\
d / \mathrm{mm}\end{array}$ & $\begin{array}{c}\text { Average } \\
\text { pressure } \\
\text { angle } /\left(^{\circ}\right)\end{array}$ & $\begin{array}{c}\text { Spiral } \\
\text { angle } /\left(^{\circ}\right)\end{array}$ & Hand & $\begin{array}{c}\text { Cutter } \\
\text { radius } / \mathrm{mm}\end{array}$ \\
\hline Pinion & 9 & 12 & 76 & 129.8 & 20 & 45 & Left & \\
\hline Wheel & 41 & 12 & 70 & 492.0 & 20 & 45 & Right & 177.8 \\
\hline
\end{tabular}

Table 1 Basic parameters of a hypoid gear pair

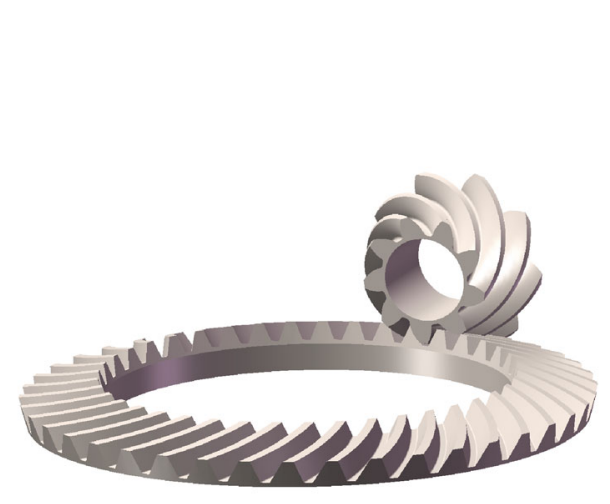

Fig. 2 Gleason hypoid gear pair studied in this work.

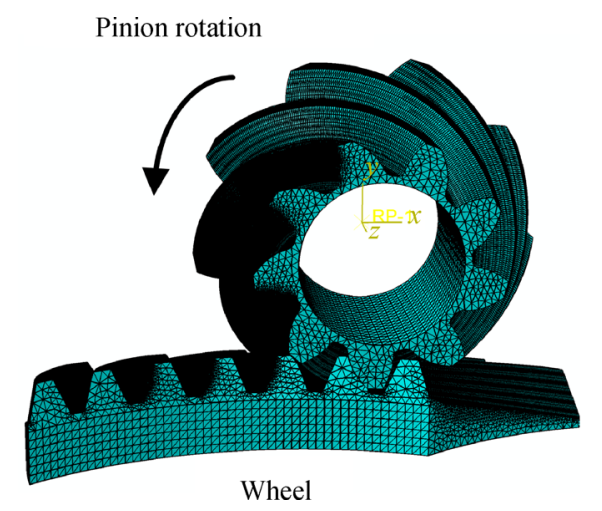

Fig. 3 Finite element contact model of a gear pair 
complicated road conditions. The average value of the load-time history is $T_{2}=2153 \mathrm{~N} \cdot \mathrm{m}$, as depicted in Fig. 4 . When the vehicle is driving on a complicated road, the load fluctuates significantly due to the unevenness of the road surface.

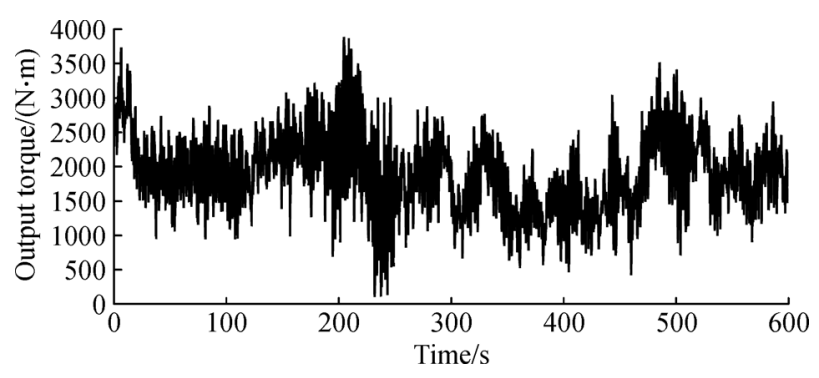

Fig. 4 Typical torque history of the output axle.

Statistical counting was conducted using the widely accepted rain flow method to derive the amplitude-mean rain flow matrix. The resultant torque amplitude-mean frequency histogram is shown in Fig. 5. Subsequently, the amplitude-mean probability distribution function was determined. Then, the two-dimension load spectrum was compiled, based on which the one-dimensional load spectrum was generated through the Goodman equivalent damage rule [27]. Finally, the one-dimensional standard load spectrum was used in fatigue life estimation.

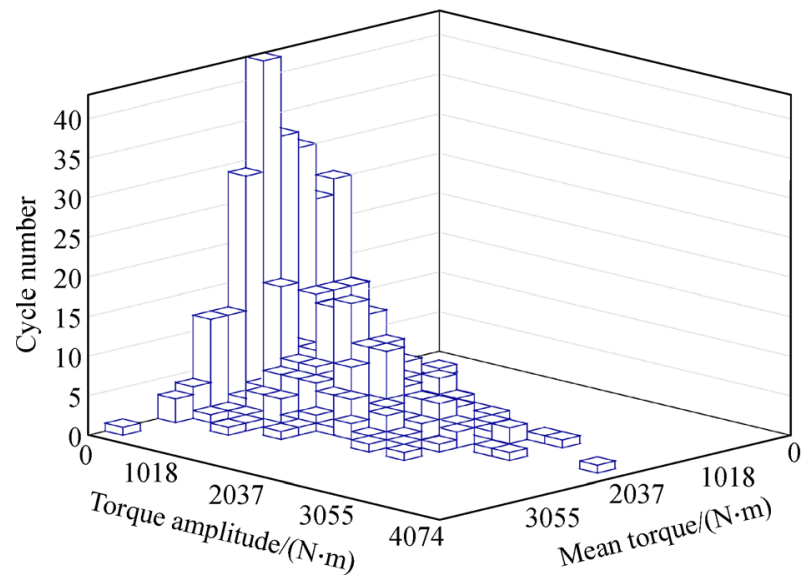

Fig. 5 Torque mean amplitude frequency histogram.

The least squares method was used to test the distribution of the mean and amplitude frequency. Logarithmic normal, three-parameter Weibull, Weibull, and normal distributions were fitted. The results showed that the torque amplitude follows the Weibull distribution, and the mean torque follows the normal distribution. Figure 6(a) shows that the statistical amplitude frequency follows the Weibull distribution. Figure 6(b) depicts the fitted amplitude probability density curve, and Fig. 6(c) shows that the statistical mean frequency follows the normal distribution. Figure 6(d) illustrates the fitted mean probability density curve.

The mean value and amplitude of torque are independent variables, and the two-dimension load spectrum relates to both variables. Therefore, the joint probability density function of the mean and amplitude is defined as

$$
f(x, y)=f(x) f(y),
$$

where $x$ stands for the mean and $y$ refers to the amplitude.

$$
\begin{aligned}
f(x, y)= & f(x) f(y) \\
= & 0.001002 \exp \left(\frac{\frac{x-2037}{1205}+0.08661}{0.392}\right)^{2} \\
& \times 0.0784 y^{-0.5802} \exp \left(-0.1868 y^{0.4198}\right) .
\end{aligned}
$$

The mean and amplitude of load were divided into eight grades. The mean was divided with an equal spacing, and the proportional coefficients were $0.125,0.25,0.375,0.5$, $0.625,0.75,0.875$, and 1 . The amplitude was divided with an unequal spacing, and the coefficients were $1,0.95,0.85$, $0.725,0.575,0.425,0.275$, and 0.125 .

The joint probability density function was then used to calculate the frequency of each load interval. The formula is expressed as

$$
N=N^{\prime} \int_{S_{\mathrm{a} 1}}^{S_{\mathrm{a} 2}} \int_{S_{\mathrm{m} 1}}^{S_{\mathrm{m} 2}} f(x, y) \mathrm{d}(x, y),
$$

where $N$ is the cycle number, $S_{\mathrm{a} 1}$ and $S_{\mathrm{a} 2}$ are the integral lower and upper limits of amplitude, respectively, $S_{\mathrm{m} 1}$ and $S_{\mathrm{m} 2}$ are the integral lower and upper limits of the mean, respectively, and $N^{\prime}$ is the cumulative frequency.

The 600-second data of torque shown in Fig. 4 are insufficient to represent the entire loading history. Therefore, cumulative loading cycles should be extended to the well-recognized threshold of $10^{6}$ cycles. To reflect a more realistic load history experienced during the entire life cycle, the two-dimension load spectrum is shown in a tabular form in Table 2.

The German company LBF [28] developed an eightlevel program load spectrum, which has been widely used for fatigue life estimation of truck gears. The main advantage of such a standard load spectrum is that it accurately reflects the actual loading history conditions of vehicles. On the basis of this method and the Goodman equivalent damage rule, the one-dimensional standard load spectrum with zero mean stress for the bevel gear was generated in this work, as shown in Table 3.

\subsection{Damage accumulation rules}

Many fatigue damage accumulation rules [29,30] have been proposed, and they can be classified into three main types, namely, linear, bilinear, and nonlinear. The Miner 

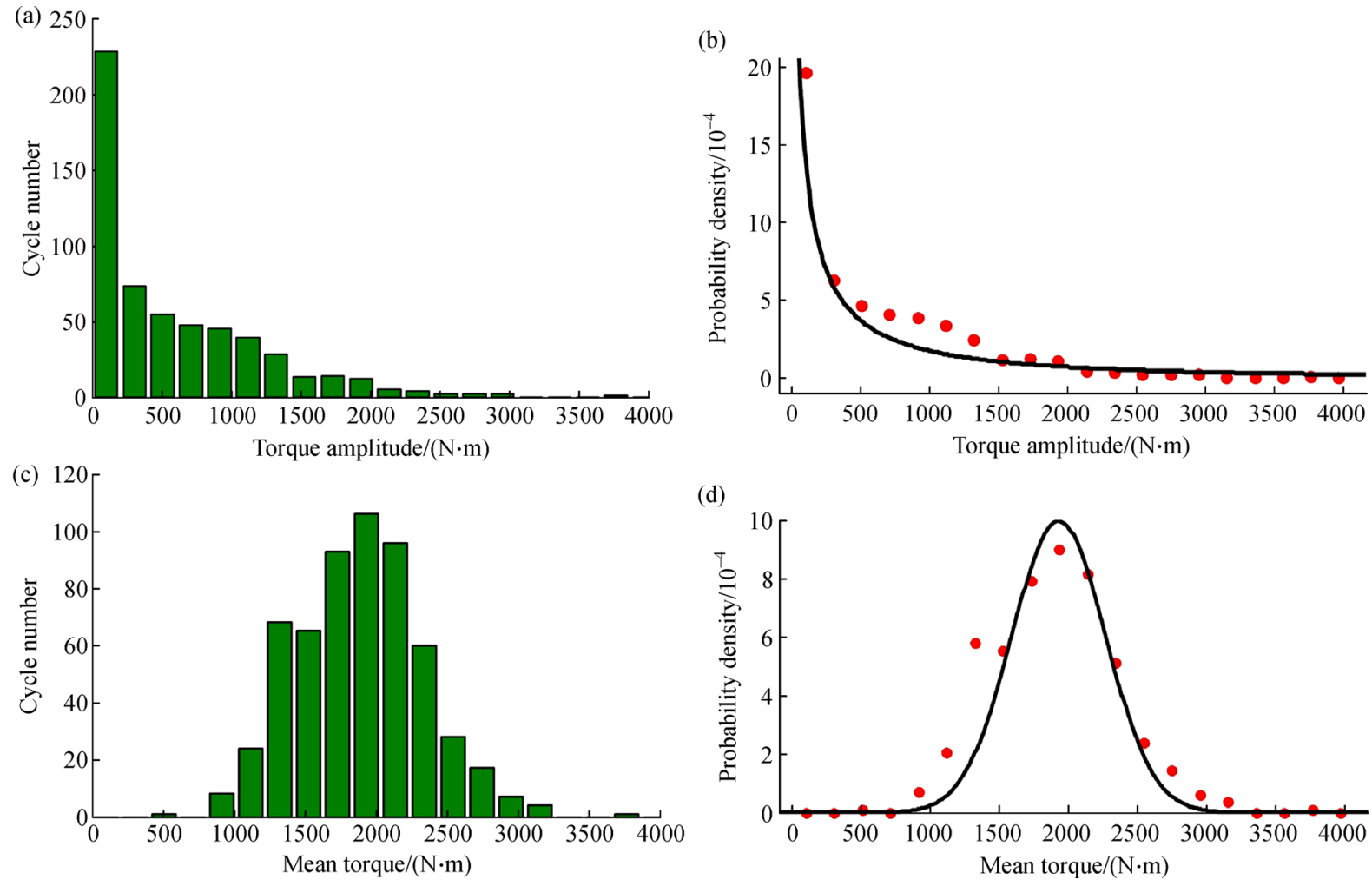

Fig. 6 Probability densities of mean torque and amplitude. (a) Torque amplitude frequency histogram; (b) torque amplitude probability density; (d) mean torque frequency histogram; (e) mean torque probability density.

Table 2 The matrix of loading cycle under various amplitudes and mean values of torque

\begin{tabular}{|c|c|c|c|c|c|c|c|c|}
\hline \multirow{2}{*}{ Mean/(N·m) } & \multicolumn{8}{|c|}{ Loading cycle number } \\
\hline & $496.5 \mathrm{~N} \cdot \mathrm{m}$ & $1092.3 \mathrm{~N} \cdot \mathrm{m}$ & $1688 \mathrm{~N} \cdot \mathrm{m}$ & $2284 \mathrm{~N} \cdot \mathrm{m}$ & $2879.8 \mathrm{~N} \cdot \mathrm{m}$ & $3376.3 \mathrm{~N} \cdot \mathrm{m}$ & $3773.5 \mathrm{~N} \cdot \mathrm{m}$ & $3972 \mathrm{~N} \cdot \mathrm{m}$ \\
\hline$\overline{496.5}$ & 367 & 42 & 14 & 7 & 3 & 2 & 0 & 0 \\
\hline 993.0 & 12400 & 1430 & 487 & 222 & 116 & 57 & 31 & 12 \\
\hline 1489.5 & 119000 & 13600 & 4660 & 2120 & 1110 & 549 & 300 & 117 \\
\hline 1986.0 & 330000 & 37800 & 12900 & 5890 & 3080 & 1520 & 829 & 325 \\
\hline 2482.5 & 270000 & 31000 & 10600 & 4830 & 2530 & 1250 & 680 & 266 \\
\hline 2979.0 & 65300 & 7500 & 2560 & 1170 & 610 & 302 & 164 & 64 \\
\hline 3475.5 & 4540 & 521 & 178 & 81 & 42 & 21 & 11 & 4 \\
\hline 3972.0 & 88 & 10 & 3 & 2 & 0 & 0 & 0 & 0 \\
\hline
\end{tabular}

linear, Manson bilinear, and Corten-Dolan nonlinear rules are generally accepted in engineering practice [31].

The fatigue damage variable $D$ of the Miner linear rule is the ratio between cycle number $n$ under service stress and fatigue life $N$ of the material under this stress, and it is expressed as

$$
D=\frac{n}{N} .
$$

Under multiple stress amplitudes, the Miner damage is expressed as

$$
D=\sum D_{i}=\sum \frac{n_{i}}{N_{i}},
$$

where $D_{i}$ means the damage suffered during a loading block, $n_{i}$ is the cycle number under the $i$ th class of load, and $N_{i}$ is the fatigue life under the $i$ th load class.

The Manson bilinear rule assumes that the fatigue life consists of two stages for a two-level cyclic loading condition. As shown in Fig. 7, the fatigue damage for each 
Table 3 Eight-level standard load spectrum

\begin{tabular}{lc}
\hline Load $/(\mathrm{N} \cdot \mathrm{m})$ & Cycle number \\
\hline 600.0 & 850000 \\
1319.5 & 83700 \\
2039.3 & 26500 \\
2750.0 & 11200 \\
3470.0 & 5700 \\
4067.5 & 3200 \\
4545.0 & 1400 \\
4785.0 & 572 \\
\hline
\end{tabular}

stage is calculated individually using the linear cumulative damage rule.

For loading blocks containing more than two loading levels, the bilinear damage curve is expressed as

$$
\begin{aligned}
& Z=\frac{\ln \left[0.35\left(\frac{N_{1}}{N_{2}}\right)^{0.25}\right]}{N_{1}^{\varphi}} \\
& \varphi=\frac{1}{\ln \left(\frac{N_{1}}{N_{2}}\right)} \ln \left(\frac{\ln \left[0.35\left(\frac{N_{1}}{N_{2}}\right)^{0.25}\right]}{\ln \left[1-0.65\left(\frac{N_{1}}{N_{2}}\right)^{0.25}\right]}\right), \\
& \left\{\begin{array}{l}
n_{i, \mathrm{I}}=N_{i, \mathrm{f}} \exp \left(Z N_{i, \mathrm{f}}^{\varphi}\right), \\
n_{i, \mathrm{II}}=N_{i, \mathrm{f}}-n_{i, \mathrm{I}},
\end{array}\right.
\end{aligned}
$$

where $N_{i, \mathrm{f}}$ is the fatigue life under the $i$ th load class, $N_{1}$ represents the fatigue life at the highest stress level in the load spectrum, and $N_{2}$ is the fatigue life at the lowest stress level in the load spectrum.

According to the Corten-Dolan nonlinear rule under the action of multistage stress, high-level stress not only causes damage to the structure but also affects the damage induced by low stress. The formula for fatigue life estimation under multistage stresses has the form

$$
N=\frac{N_{1}}{\sum_{i=1}^{n} a_{i}\left(\frac{\sigma_{i}}{\sigma_{1}}\right)^{d}},
$$

where $N$ is the total fatigue life under multistage stresses, $\sigma_{1}$ represents the stress value of maximum load with a unit of MPa, $N_{1}$ is the fatigue life under stress level $\sigma_{1}, \sigma_{i}$ is the stress value for the $i$ th load class, $a_{i}$ represents the ratio of cycle number of the $i$ th load class stress to the total cycle number, and $d$ is the material constant. In the absence of test data, Corten assumed that $d / m=0.85$, where $m$ is the slope of the $S-N$ curve.

\section{Results and discussion}

\subsection{Fatigue life prediction under constant load conditions}

Figure 8 plots the distributions of contact pressure and von Mises stress under a constant output torque of $500 \mathrm{~N} \cdot \mathrm{m}$. High contact pressure was distributed in the middle of the tooth surface. The maximum contact pressure was 590.65 $\mathrm{MPa}$, and the maximum von Mises stress on the tooth surface was $315.5 \mathrm{MPa}$.

Figure 9 shows the calculated fatigue life of the bevel gear under various constant loading conditions with the torque $T_{2}$ increasing from 1000 to $5000 \mathrm{~N} \cdot \mathrm{m}$. As the load level increased, the minimum fatigue life of the bevel gear decreased significantly from $7.1 \times 10^{8}$ to $1.45 \times 10^{6}$.

The material point with the minimum fatigue life was selected as a representative, and the evolutions of various stress components experienced by this material point under the loading condition $T_{2}=3000 \mathrm{~N} \cdot \mathrm{m}$ are displayed in Fig. 10. The shear stress components presented different tendencies during a meshing cycle compared with the normal components. The normal stress components remained compressive, whereas the shear components changed their signs during the loading cycle, indicating a typical multiaxial state with considerable mean stress.

When lives at several constant loading levels are
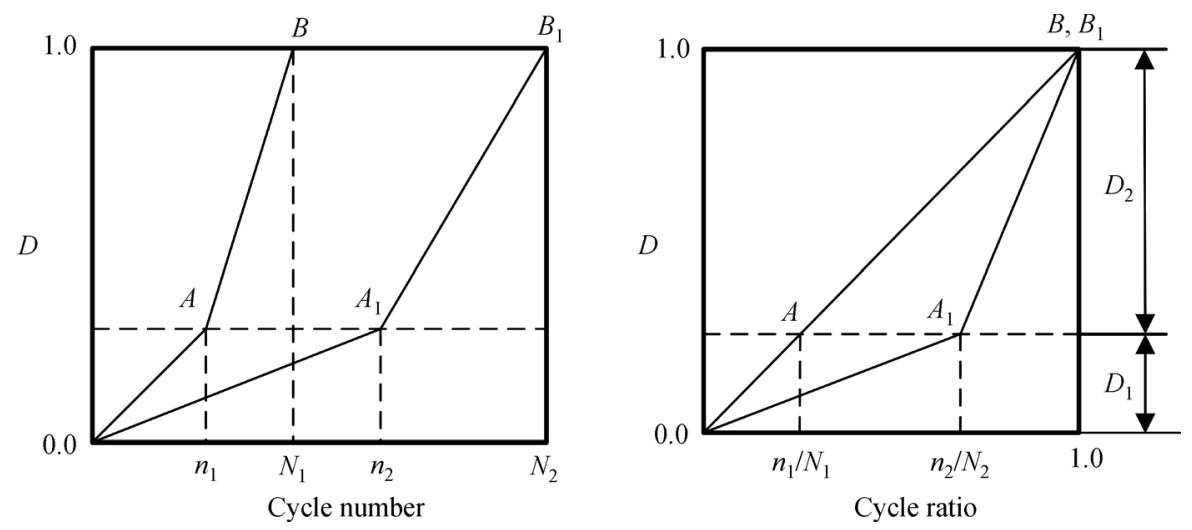

Fig. 7 Manson bilinear rule. 


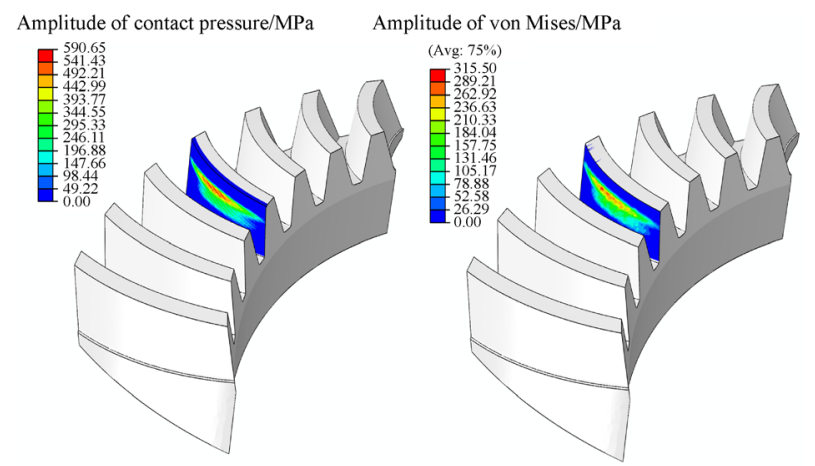

Fig. 8 Distributions of contact pressure and von Mises at a torque of $500 \mathrm{~N} \cdot \mathrm{m}$.

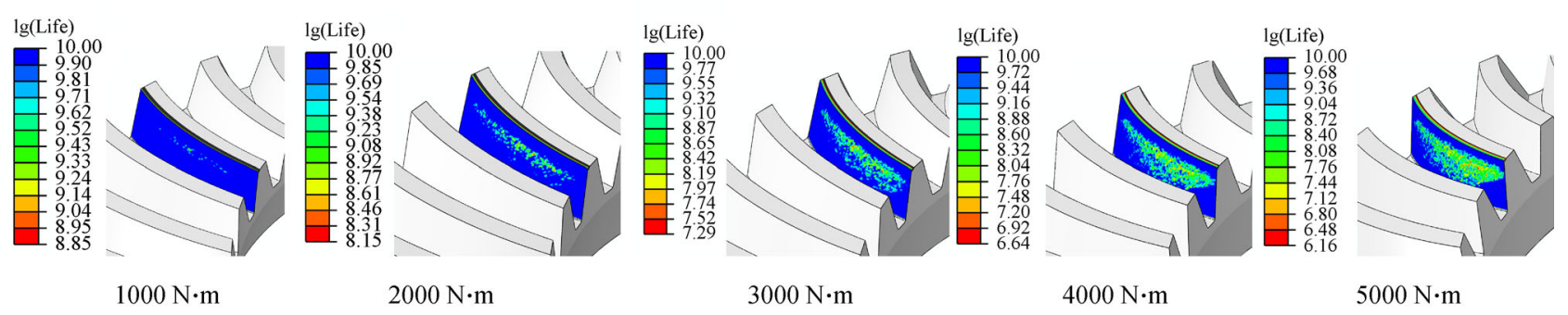

Fig. 9 Contact fatigue life at various loading levels.

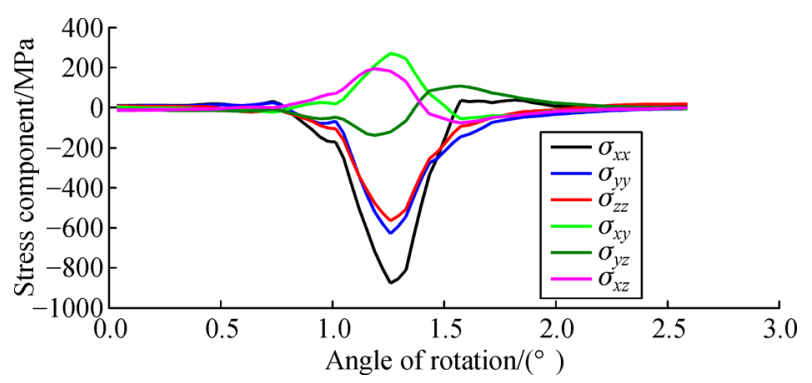

Fig. 10 Evolutions of stress components during a loading cycle.

estimated, the RCF $S-N$ curve can indicate the relation between failure cycle $N_{\mathrm{f}}$ and the maximum contact pressure, as shown in Fig. 11.

For the classical $S-N$ curve of contact fatigue, the relationship between stress and cycle number can be expressed by many forms of empirical equations and can be approximated linearly on a $\log -\log$ graph. The most common empirical equation is the Basquin formula [32]:

$$
S=\sigma_{\mathrm{f}}^{\prime}\left(2 N_{\mathrm{f}}\right)^{b} .
$$

Use the logarithm of both sides to obtain

$$
\lg S=b \lg N_{\mathrm{f}}+C,
$$

where $S$ is the stress amplitude in MPa, $C$ is the constant, and $N_{\mathrm{f}}$ is the cycle number to failure.

The contact fatigue $S-N$ curve of the driven gear can be

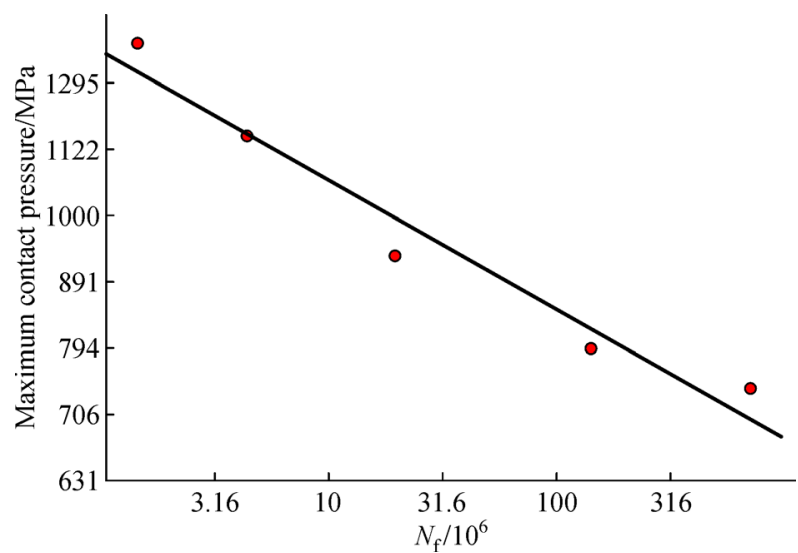

Fig. 11 Contact fatigue $S-N$ curve of driven gear.

curve-fitted as follows:

$$
\lg S=-10 \lg N_{\mathrm{f}}+23.9 .
$$

\subsection{Special load spectrum case}

Before the application of the fluctuating loading condition, a special load spectrum consisting of only one constant torque was assumed to investigate the effect of three commonly used damage accumulation rules. The constant load was set as $T_{2}=2153 \mathrm{~N} \cdot \mathrm{m}$. The aforementioned $S-N$ curve indicates that the life under this specific constant 
loading condition is $N_{\mathrm{f}}=7.1 \times 10^{7}$.

If the simple Miner linear rule is applied, since the damage is expressed as

$$
D=\frac{n}{N_{\mathrm{f}}},
$$

we have

$$
N=N_{\mathrm{f}}=7.1 \times 10^{7} .
$$

If the Manson bilinear rule is adopted, given that

$$
\begin{gathered}
N_{\mathrm{f}, \mathrm{I}}=N_{\mathrm{f}, \mathrm{II}}=3.55 \times 10^{7}, \\
D_{\mathrm{I}}=\frac{n}{N_{\mathrm{f}, \mathrm{I}}}, D_{\mathrm{II}}=\frac{n}{N_{\mathrm{f}, \mathrm{II}}},
\end{gathered}
$$

we have

$$
D_{\text {I }}=1, N_{1}=3.55 \times 10^{7} .
$$

Considering that $D_{\mathrm{II}}=1, N_{2}=3.55 \times 10^{7}$, from which we can readily see $N=N_{\mathrm{f}}=7.1 \times 10^{7}$.

If the Corten-Dolan nonlinear rule is applied, then

$$
N=\frac{N_{1}}{\sum_{i=1}^{n} a_{i}\left(\frac{\sigma_{i}}{\sigma_{1}}\right)^{d}}=7.1 \times 10^{7} .
$$

In a constant loading case, because no load sequence is involved, the selection of damage accumulation rule has no effect on fatigue life. This section illustrates the basic procedure for life estimation based on a damage accumulation law.

\subsection{Load spectrum case}

The aforementioned fluctuating load spectrum consisting of eight levels of torque was applied in this section.

With regard to the Miner linear rule,

$$
\begin{aligned}
D & =\sum \frac{n_{i}}{N_{i}}, \\
D= & \frac{850000}{10^{10}}+\frac{83700}{10^{8.8}}+\frac{26500}{10^{8}}+\frac{11200}{10^{7.36}}+\frac{5700}{10^{6.9}} \\
& +\frac{3200}{10^{6.6}}+\frac{1400}{10^{6.37}}+\frac{572}{10^{6.27}} \\
= & 0.0034 .
\end{aligned}
$$

When $D=1$, fatigue failure occurs. Thus, fatigue life is calculated as

$$
N_{\mathrm{f}, \text { Miner }}=2.9 \times 10^{8} .
$$

As for the Manson bilinear rule, according to Eqs. (8)(10),

$$
N_{1}=1.86 \times 10^{6}, N_{2}=10^{10}, \varphi=0.44, Z=-1.84 \times 10^{3} .
$$$$
\left\{\begin{array} { l } 
{ n _ { 1 , \mathrm { I } } = 7 . 6 \times 1 0 ^ { 4 } , } \\
{ n _ { 1 , \mathrm { II } } = 1 7 8 . 6 \times 1 0 ^ { 4 } , }
\end{array} \quad \left\{\begin{array}{l}
n_{2, \mathrm{I}}=1.27 \times 10^{5}, \\
n_{2, \mathrm{II}}=22.13 \times 10^{5},
\end{array}\right.\right.
$$

$$
\left\{\begin{array} { l } 
{ n _ { 3 , \mathrm { I } } = 3 . 9 8 \times 1 0 ^ { 5 } , } \\
{ n _ { 3 , \mathrm { II } } = 3 5 . 8 2 \times 1 0 ^ { 5 } , }
\end{array} \quad \left\{\begin{array}{l}
n_{4, \mathrm{I}}=1.46 \times 10^{6} \\
n_{4, \mathrm{II}}=6.48 \times 10^{6}
\end{array}\right.\right.
$$

$$
\begin{gathered}
\left\{\begin{array}{l}
n_{5, \mathrm{I}}=7.9 \times 10^{6}, \\
n_{5, \mathrm{II}}=15 \times 10^{6},
\end{array},\left\{\begin{array}{l}
n_{6, \mathrm{I}}=5.7 \times 10^{7}, \\
n_{6, \mathrm{II}}=4.3 \times 10^{7},
\end{array}\right.\right. \\
\left\{\begin{array} { l } 
{ n _ { 7 , \mathrm { I } } = 4 . 9 3 \times 1 0 ^ { 8 } , } \\
{ n _ { 7 , \mathrm { II } } = 1 . 3 8 \times 1 0 ^ { 8 } , }
\end{array} \quad \left\{\begin{array}{l}
n_{8, \mathrm{I}}=9.3 \times 10^{9}, \\
n_{8, \mathrm{II}}=178.6 \times 10^{9} .
\end{array}\right.\right.
\end{gathered}
$$

The following relationship should be satisfied:

$$
\begin{aligned}
\sum_{1}^{k} \frac{n_{i}}{N_{i, \mathrm{I}}} & =1, \\
\sum_{1}^{k} \frac{n_{i}}{N_{i, \mathrm{II}}} & =1 .
\end{aligned}
$$

We have

$$
D_{\mathrm{I}}=\sum_{1}^{8} \frac{n_{i}}{N_{i, \mathrm{I}}}=0.033 .
$$

When $D_{\mathrm{I}}=1, N_{\mathrm{I}}=3.1 \times 10^{7}$.

$$
D_{\text {II }}=\sum_{1}^{8} \frac{n_{i}}{N_{i, \mathrm{II}}}=0.006 .
$$

When $D_{\text {II }}=1, N_{\text {II }}=1.67 \times 10^{8}$. Thus, the life with the Manson criterion is calculated as

$$
N_{\text {f,Manson }}=1.98 \times 10^{8} .
$$

When the Corten-Dolan nonlinear rule is applied, slope $m$ and material constant $d$ can be determined from the given $S-N$ curve as follows: $m=10$ and $d=8.5$.

Therefore, we have

$$
N=\frac{N_{1}}{\sum_{i=1}^{n} a_{i}\left(\frac{\sigma_{i}}{\sigma_{1}}\right)^{d}}=\frac{10^{6.27}}{0.007}=2.66 \times 10^{8} .
$$

The Manson bilinear rule gives rise to the minimum fatigue life, and the Miner linear rule provides the maxima because the Miner linear rule assumes fatigue damage as a stationary process independent of the loading level and sequence. The Manson bilinear rule divides fatigue damage into two stages, which can be determined 
according to the loading sequence of high and low loads, as shown in Fig. 12. When a multistage load case is assumed in which more than two loading levels are involved, the total damage estimated by the Manson bilinear rule is mainly determined by the highest and lowest levels. Final failure is expected to occur when the total damage is less than unity, which indicates a shorter life compared with the Miner linear rule. According to the Corten-Dolan nonlinear rule, all damages are related to the maximum stress and the relationship between the maximum stress and each stress level. Owing to the consideration of the relationship between the current stress level and the maximum one, the damage rate at each stress level increases compared with that in the Miner linear rule, resulting in a reduced fatigue life. Notably, the life magnitude predicted by the CortenDolan rule significantly depends on the selection of parameter $d$, which should be determined experimentally.

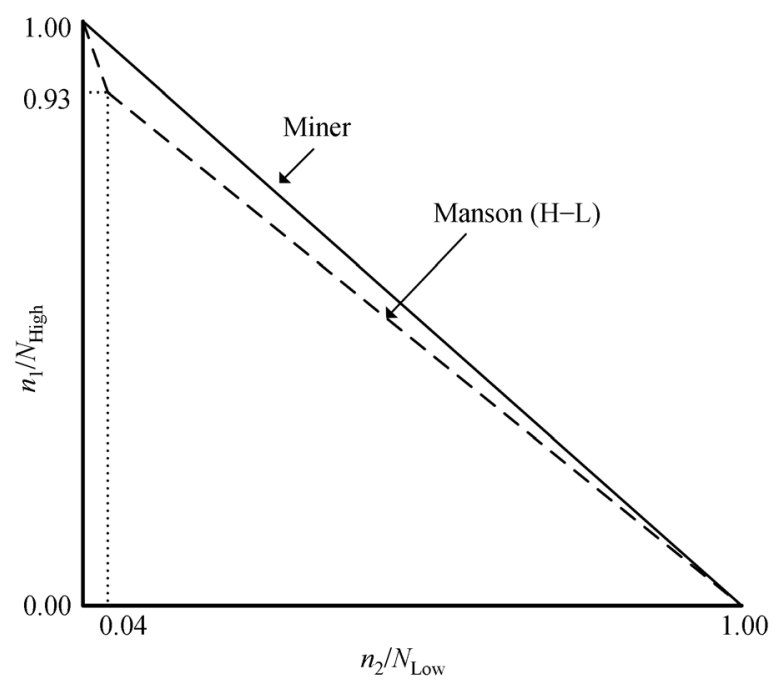

Fig. 12 Damage with two-stage loading under different criteria.

\section{Conclusions}

A systematic numerical model that considers multiaxial fatigue and the load spectrum was developed to thoroughly understand the contact failure process of bevel gears. Various fatigue damage accumulation rules were also discussed, and the following conclusions were obtained.

1) The proposed numerical methodology can be utilized in the contact fatigue life estimation of bevel gears under given load spectrums because the multiaxial stress response is correctly captured in the repeated contact loading process. This methodology can be a promising approach for fatigue analysis of other types of gears or bearings because it allows a flexible selection of any other damage accumulation rule.

2) In a constant loading case, because no load sequence is involved, the selection of the damage accumulation rule has no effect on fatigue life. Under a fluctuating loading spectrum, the Miner rule provides the most optimistic result among three rules, and the Manson bilinear rule produces the most conservative one.

Acknowledgements The work was supported by the National Natural Science Foundation of China (Grant No. U1864210), the Open Foundation of the State Key Laboratory of Mechanical Transmissions (Grant No. SKLMTKFKT-201701), and Chongqing Research Program of Basic Research and Frontier Technology (Grant No. cstc2017jcyjAX0103).

Open Access This article is licensed under a Creative Commons Attribution 4.0 International License, which permits use, sharing, adaptation, distribution and reproduction in any medium or format, as long as you give appropriate credit to the original author(s) and the source, provide a link to the Creative Commons license, and indicate if changes were made.

The images or other third-party materials in this article are included in the article's Creative Commons license, unless indicated otherwise in a credit line to the material. If a material is not included in the article's Creative Commons license and your intended use is not permitted by statutory regulation or exceeds the permitted use, you will need to obtain permission directly from the copyright holder.

To view a copy of this license, visit http://creativecommons.org/licenses/ by $/ 4.0 /$.

\section{References}

1. Niemann G, Rettig H, Lechner G. Scuffing tests on gear oils in the FZG apparatus. A S L E Transactions, 1961, 4(1): 71-86

2. Höhn B R, Michaelis K, Doleschel A. Frictional behaviour of synthetic gear lubricants. Tribology Series, 2001, 39: 759-768

3. He H, Liu H, Zhu C, et al. Study of rolling contact fatigue behavior of a wind turbine gear based on damage-coupled elastic-plastic model. International Journal of Mechanical Sciences, 2018, 141: $512-519$

4. Fernandes P J L, McDuling C. Surface contact fatigue failures in gears. Engineering Failure Analysis, 1997, 4(2): 99-107

5. Liu H, Liu H, Zhu C, et al. Evaluation of contact fatigue life of a wind turbine gear pair considering residual stress. Journal of Tribology, 2018, 140(4): 041102

6. Carpinteri A, Spagnoli A, Vantadori S. A review of multiaxial fatigue criteria for random variable amplitude loads. Fatigue \& Fracture of Engineering Materials \& Structures, 2017, 40(7): 10071036

7. Wang W, Liu H, Zhu C, et al. Effect of the residual stress on contact fatigue of a wind turbine carburized gear with multiaxial fatigue criteria. International Journal of Mechanical Sciences, 2019, 151: 263-273

8. Wang W, Liu H, Zhu C, et al. Micromechanical analysis of gear fatigue-ratcheting damage considering the phase state and inclusion. Tribology International, 2019, 136: 182-195

9. Wu Z R, Hu X T, Song Y D. Multiaxial fatigue life prediction for titanium alloy TC4 under proportional and nonproportional loading. International Journal of Fatigue, 2014, 59: 170-175

10. Zhu S P, Yu Z Y, Correia J, et al. Evaluation and comparison of critical plane criteria for multiaxial fatigue analysis of ductile and brittle materials. International Journal of Fatigue, 2018, 112: 279288

11. Litvin F L, Fuentes A, Hayasaka K. Design, manufacture, stress 
analysis, and experimental tests of low-noise high endurance spiral bevel gears. Mechanism and Machine Theory, 2006, 41(1): 83-118

12. Sekercioglu T, Kovan V. Pitting failure of truck spiral bevel gear. Engineering Failure Analysis, 2007, 14(4): 614-619

13. Bhavi I, Kuppast V, Kurbet S. Experimental setup and methodology to carryout fatigue testing of spiral bevel gears used in differential gear box using NVH approach. Applied Mechanics and Materials, 2016, 852: 545-550

14. Ural A, Heber G, Wawrzynek P A, et al. Three-dimensional, parallel, finite element simulation of fatigue crack growth in a spiral bevel pinion gear. Engineering Fracture Mechanics, 2005, 72(8): $1148-1170$

15. Deng S, Hua L, Han X, et al. Finite element analysis of contact fatigue and bending fatigue of a theoretical assembling straight bevel gear pair. Journal of Central South University, 2013, 20(2): 279-292

16. Liu F, Wu W, Hu J, et al. Design of multi-range hydro-mechanical transmission using modular method. Mechanical Systems and Signal Processing, 2019, 126: 1-20

17. Liu S, Song C, Zhu C, et al. Investigation on the influence of work holding equipment errors on contact characteristics of face-hobbed hypoid gear. Mechanism and Machine Theory, 2019, 138: 95-111

18. Medepalli S, Rao R. Prediction of road loads for fatigue design-A sensitivity study. International Journal of Vehicle Design, 2000, 23(1-2): 161-175

19. Liu X, Li D, Lv W, et al. Research on analysis approach of strength and fatigue life of horizontal axis wind turbine hub. Acta Energiae Solaris Sinica, 2012, 5: 18-23 (in Chinese)

20. Shinde V, Jha J, Tewari A, et al. Modified rainflow counting algorithm for fatigue life calculation. In: Seetharamu S, Rao K, Khare R, eds. Proceedings of Fatigue, Durability and Fracture Mechanics. Singapore: Springer, 2018, 381-387

21. Mayer H, Ede C, Allison J E. Influence of cyclic loads below endurance limit or threshold stress intensity on fatigue damage in cast aluminium alloy 319-T7. International Journal of Fatigue, 2005,
27(2): 129-141

22. Hu H, Yan Y M. Light bus drive axle design. Applied Mechanics and Materials, 2013, 380-384: 17-22

23. Carpinteri A, Spagnoli A. Multiaxial high-cycle fatigue criterion for hard metals. International Journal of Fatigue, 2001, 23(2): 135145

24. Patra A P, Bidhar S, Kumar U. Failure prediction of rail considering rolling contact fatigue. International Journal of Reliability Quality and Safety Engineering, 2010, 17(03): 167-177

25. Brown $\mathrm{M} \mathrm{W}$, Miller K J. A theory for fatigue failure under multiaxial stress-strain conditions. Proceedings of Institution of Mechanical Engineers, 1973, 187(1): 745-755

26. Kumbhar S V, Kulkarni V, Tayade R M. Low cycle fatigue analysis of after treatment device induced due to thermal load by using finite element analysis. Applied Mechanics and Materials, 2014, 592594: 1104-1108

27. Wen B Z, Li J M, Pei Z T, et al. Statistical analysis of loader's drive axle housing random load spectrum. Advanced Materials Research, 2011, 338: 456-459

28. Grubisic V, Fischer G, Heinritz M. Design Optimization of Forged Wheel Hubs for Commercial Vehicles. SAE Technical Paper 841706, 1984

29. Batsoulas Nikolaos D. Cumulative Fatigue Damage: CDM-Based Engineering Rule and Life Prediction Aspect. Steel Research International, 2016, 87(12): 1670-1677

30. Rege K, Pavlou D G. A one-parameter nonlinear fatigue damage accumulation model. International Journal of Fatigue, 2017, 98 : 234-246

31. Zhao L H, Cai H C, Wang T, et al. Durability assessment of automotive structures under random variable amplitude loading. Advances in Mechanical Engineering, 2018, 10(4): 1687814 018771766

32. Han Q, Guo Q, Yin Y, et al. Effects of strain ratio on fatigue behavior of G20Mn5QT cast steel. Transactions of Tianjin University, 2016, 22(4): 302-307 